\title{
Assessing spatial inequalities in accessing community pharmacies: a mixed geographically weighted approach
}

\author{
Alexander Domnich, Lucia Arata, Daniela Amicizia, Alessio Signori, Roberto Gasparini, \\ Donatella Panatto \\ Department of Health Sciences, University of Genoa, Italy
}

\begin{abstract}
Geographical accessibility is an important determinant for the utilisation of community pharmacies. The present study explored patterns of spatial accessibility with respect to pharmacies in Liguria, Italy, a region with particular geographical and demographic features. Municipal density of pharmacies was proxied as the number of pharmacies per capita and per $\mathrm{km}^{2}$, and spatial autocorrelation analysis was performed to identify spatial clusters. Both non-spatial and spatial models were constructed to predict the study outcome. Spatial autocorrelation analysis showed a highly significant clustered pattern in the density of pharmacies per capita $(I=0.082)$ and per $\mathrm{km}^{2}(I=0.295)$. Potentially under-supplied areas were mostly located in the mountainous hinterland. Ordinary least-squares (OLS) regressions established a significant positive relationship between the density of pharmacies and income among municipalities located at high altitudes, while no such association was observed in lower-lying areas. However, residuals of the OLS models were spatially auto-correlated. The best-fitting mixed geographically
\end{abstract}

Correspondence: Alexander Domnich, Department of Health Sciences, University of Genoa, via Pastore 1, 16132 Genoa, Italy

Tel: $+39.010 .3538524-$ Fax: +39.010 .3538541$

E-mail: alexander.domnich@gmail.com

Key words: Community pharmacies; Geographical accessibility; Access inequalities; Geographically weighted regression.

Contributions: $\mathrm{AD}$ and RG conceived and designed the study; $\mathrm{AD}$, LA and DA collected data; $\mathrm{AD}$, LA and AS analysed data; DP and RG coordinated the study; AD, LA and DP wrote the manuscript.

Conflict of interest: the authors declare no potential conflict of interest.

Acknowledgments: the authors thank Dr. Bernard Patrick for his linguistic review of the manuscript.

Received for publication: 27 January 2016.

Revision received: 29 April 2016.

Accepted for publication: 23 May 2016.

(C) Copyright A. Domnich et al., 2016

Licensee PAGEPress, Italy

Geospatial Health 2016; 11:457

doi:10.4081/gh.2016.457

This article is distributed under the terms of the Creative Commons Attribution Noncommercial License (CC BY-NC 4.0) which permits any noncommercial use, distribution, and reproduction in any medium, provided the original author(s) and source are credited. weighted regression (GWR) models outperformed the corresponding OLS models. Pharmacies per capita were best predicted by two local predictors (altitude and proportion of immigrants) and two global ones (proportion of elderly residents and income), while the local terms population, mean altitude and rural status and the global term income functioned as independent variables predicting pharmacies per $\mathrm{km}^{2}$. The density of pharmacies in Liguria was found to be associated with both socio-economic and landscape factors. Mapping of mixed GWR results would be helpful to policy-makers.

\section{Introduction}

Among the various healthcare facilities, community pharmacies (henceforth referred to as pharmacies) are the most easily accessible for laypeople in that individuals can enter a pharmacy without an appointment and receive professional advice immediately. Moreover, pharmacies are increasingly diversifying and already offer a number of complementary services, such as screening, disease prevention and harm-reduction interventions (Xu and Rojas-Fernandez, 2003; Benrimoj and Frommer, 2004; Stopka et al., 2013). Geographical access to healthcare services is one of the determinants with respect to their utilisation and this parameter may produce two diametrically opposite effects. Thus, people living in areas with an abundant supply of healthcare services are more prone to utilise those services (supplierinduced demand); by contrast, zones where healthcare provision is low may be subject to so-called supplier-suppressed demand (Rice and Smith, 2001). Spatial inequalities in healthcare provision occur in both developing countries (Kumar, 2004; Abolhallaje et al., 2014) and industrialised ones (Houghton, 2005; Perez and Decoupigny, 2009). Limited geographical access not only reduces the availability of pharmaceuticals but also limits recommendations regarding their use (Norris et al., 2014). Qato et al. (2014) and Amstislavski et al. (2012) have even coined the terms pharmacy deserts and medication deserts, respectively, to describe neighbourhoods where geographic access to pharmacies and the availability of commonly used drugs are poor.

Research has shown that geographical access to pharmacies depends on several factors, such as socio-economic determinants (Casey et al., 2002; Amstislavski et al., 2012; Qato et al., 2014) including levels of deprivation (Ward et al., 2014; Todd et al., 2014), community segregation (Qato et al., 2014), landscape features (Perez and Decoupigny, 2009) and degree of urbanity vis-à-vis remoteness (Lin, 2004; Todd et al., 2014; Norris et al., 2014). Among these, urban-rural inequalities are of particular relevance in Italy, since rural areas account for more than $90 \%$ of the surface area and host about $57 \%$ of the population. As in other countries, Italian rural areas are characterised by a high concentration of elderly residents and are subject to depopulation, especially in some regions (OECD, 2009). It should how- 
ever be borne in mind that rural areas are not, even when located in the same region, homogeneous in terms of geomorphologic characteristics, e.g., altitude. Analogously, not all mountainous areas are rural, and many residents live in urban centres. Compared with lowland areas, however, the people living in mountainous areas are often penalised by complex physical topography, remoteness, low population density and significant population loss, all of which may negatively influence the provision of services (Schuler et al., 2004). Indeed, access to primary healthcare in the Province of Cuneo in Piedmont, Italy has been found to be lower in its mountainous areas than in the plains (Perez and Decoupigny, 2009). To guarantee more equitable access to pharmaceuticals, single nations have adopted different legislative and regulatory strategies (WHO, 2001; Vogler et al., 2014). In Italy, a new deregulatory reform became law (Italian Republic, 2012) in 2012. In terms of pharmacy licensing, the reform aimed to increase the number of pharmacies and ensure more competitive and broader pharmaceutical services by relaxing previous restrictions (Garattini et al., 2012). Indeed, it has been claimed that in Italy the regulations governing pharmacies are anti-competitive (Antitrust Authority, 1998). The new law loosened the demographic criterion and fixed the number of inhabitants per pharmacy at 3300 (instead of 4000 and 5000 per pharmacy in municipalities with more than or less than 12,500 inhabitants, respectively) also establishing that additional pharmacies might be opened if the above criterion was exceeded by $50 \%$ (1650 inhabitants). Additional pharmacies up to $5 \%$ of the existing number may be opened in crowded zones (e.g., in proximity to stations). According to this legislation, the pharmaceutical service must also be ensured in remote and under-populated areas. As a result of the new legislative degree, the number of pharmacies is destined to grow (Farma.For, 2012), and Garattini et al. (2012) have estimated that an increase of more than $20 \%$ pharmacy licenses can be expected. While the number of pharmacies per population is a well-recognised and widely used indicator ( $\mathrm{Xu}$ and RojasFernandez, 2003; Moïse and Docteur, 2007; Amstislavski et al., 2012), the number of pharmacies within a certain geographical or administrative area provides additional useful insights into the accessibility to pharmaceuticals: the fewer pharmacies there are within a zone, the farther a consumer has to travel to purchase needed medicines (Moïse and Docteur, 2007).

In both the Italian and European contexts, Liguria has clearly distinguishable features of both a demographic and geographic nature. The region's concentration of elderly residents is among the highest in Europe (Eurostat, 2015). The fact that this hilly-mountainous region occupies a long, narrow strip of the Ligurian coast creates several logistic challenges in the face of the expected increase of the number of pharmacies, making it useful to rationalise the pharmaceutical supply in a more equal manner throughout the region. We have hypothesised some degree of geographical variation with reagrd to the density of pharmacies at the municipal level across the region; indeed it has already been shown that both health-related outcomes and healthcare supply vary spatially (Odoi and Busingye, 2014; Yao et al., 2015). The present study aimed: i) to explore the patterns of potential spatial accessibility to pharmacies in Liguria from the perspective of local characteristics, and ii) to identify disparities and their sources.

\section{Materials and Methods}

\section{Study area}

Liguria is a northwestern Italian region along the Ligurian sea with relatively high population density (approximately 290 inhabitants per $\mathrm{km}^{2}$ ). With the Apennines to the East and the Alps to the West, two thirds of the region's surface is mountainous and one third hilly. Administratively, Liguria is composed of 235 municipalities (comuni) grouped into three provinces (La Spezia, Savona and Imperia) and the Metropolitan City of Genoa (previously Genoa Province). According to the geomorphologic classification (Istat, 2014), Italian municipalities are divided into totally/partially mountainous (at least $80 \%$ of the surface is above $600 \mathrm{~m}$ or has a difference in altitude $>600 \mathrm{~m}$ ) and nonmountainous areas; four fifths of Liguria's municipalities belong to the former category. In accordance with the Eurostat definition (population density $<100$ inhabitants per $\mathrm{km}^{2}$ or proportion of employees in the agricultural sector higher than the EU average), 149 municipalities are defined as rural (Istat, 2014). Although most mountainous municipalities are rural, the two above-mentioned categories are not the same: of the 187 totally/partially mountainous municipalities, only 137 are rural. Demographically, Liguria has a higher proportion (28\%) of elderly residents than any other Italian region (Istat, 2015a).

\section{Study variables and data sources}

The main geographical unit of analysis was the municipality; reference to the provincial level was occasionally made for descriptive and comparative purposes only. The outcome was pharmaceutical accessibility, as measured by two proxies, namely the number of pharmacies per 1000 inhabitants ( $\mathrm{Ph} / \mathrm{inh} a b)$ and the number of pharmacies per $\mathrm{km}^{2}\left(\mathrm{Ph} / \mathrm{km}^{2}\right)$ (Moïse and Docteur, 2007).

A set of independent variables was chosen on the basis of regional socio-economic features, previous research (Casey et al., 2002; Perez and Decoupigny, 2009; Amstislavski et al., 2012; Norris et al., 2014; Qato et al., 2014) and data availability at the municipal level. This dataset included population (1000s of inhabitants)/population density (inhabitants per $\mathrm{km}^{2}$ ), mean altitude (100 m units) above the mean sea level (msl), dummy variables of the status of rural according to the Eurostat classification (Istat, 2014), municipality $(0=$ urban), coastal municipality $(0=$ landlocked), proportion of $>65$-year-olds, $<5$-yearolds, immigrants, and a proxy of municipal income (mean declared personal income per taxpaper in 1000s of Euro).

The data on existing pharmacies were extracted (October 22, 2015) from the Italian Ministry of Health's open dataset (Ministry of Health, 2015), which is updated on a regular basis and contains a full description of single pharmacies, including their geographic location. All types of dispensing points, including main pharmacies (farmacie ordinarie), pharmacy branches (farmacie succursali), annual dispensaries (dispensari annuali) and seasonal ones (dispensari stagionali) were eligible. Pharmacies operating in Liguria and open on January 1, 2015 were included in the study. Geographic and socio-economic data were retrieved from the Italian National Institute of Statistics (Istat, 2015a, 2015b) and Ministry of Economy and Finance (2012).

\section{Data analysis}

As a preliminary step, both indicators of density of pharmacies at the provincial level were calculated and described. Municipalities without their own pharmacy were identified and their frequency compared at the provincial level. This subset was additionally analysed in order to evaluate the distance from and travelling time to the nearest pharmacy - expressed as mean [standard deviation (SD)] - located in surrounding municipalities (bordering municipalities of other regions were also considered). For this purpose, Google maps (https://maps.google.com) were used, owing to their acceptable positional accuracy (Lemke et al., 2015) and a low likelihood of significant errors in travel time estimation (Delamater et al., 2012). Availability of at least one pharmacy was compared between mountainous and non-mountainous municipalities 
by means of Fisher's exact test. The mean altitude of municipalities without a pharmacy and those with at least one pharmacy was compared by means of the $t$ test and expressed as standardised mean difference $(d)$ with $95 \%$ confidence interval (CI).

For the main study, both study outcomes were transformed by cuberoot transformation in order to ensure their approximately normal distributions. Thematic choropleth mapping with single hue or bi-polar colour progressions was used to map the local data.

Global spatial autocorrelation analysis was performed using Moran's I statistics (Moran, 1950). Negative, near zero and positive values indicate dispersed, random and cluster patterns, respectively. To compute the spatial autocorrelation analysis, $k$ nearest-neighbour spatialweights matrices were built. Since there is no universally accepted method to establish an optimal $k$ (Hassanat et al., 2014), the square root of the number of observations ( $k=15$ in this case) was used. A Monte Carlo simulation with 999 rounds was calculated in order to verify the statistical significance of $I s$.

To identify the presence of potential spatial clusters (with significantly positive $I$ ) or outliers (with significantly negative $I$ ), local spatial analysis was performed by means of local Moran's I coefficients (Anselin, 1995). Choropleth maps were subsequently created to visualise and distinguish among four types of clusters/outliers, namely high-high, i.e. hotspots that signified municipalities with a high density of pharmacies surrounded by municipalities with a high density of pharmacies, while low-low (coldspots) signified municipalities with a low density of pharmacies surrounded by municipalities with a low density of pharmacies. Low-high and high-low outcomes represented municipalities with low/high density of pharmacies surrounded by municipalities with high/low density of pharmacies, respectively.

Prediction modelling of the municipal density of pharmacies involved several steps. First, univariate ordinary least-squares (OLS) regressions were computed in order to highlight global unadjusted associations between the study outcomes and independent variables. Final multiple OLS models were then constructed by minimising the corrected Akaike's information criterion $\left(\mathrm{AIC}_{\mathrm{c}}\right)$. Considering possible multicollinearity issues, if two or more nested models showed approximately equal $\mathrm{AIC}_{\mathrm{c}}$ values, the most parsimonious one was preferred. Finally, given that the residual spatial autocorrelation is a well-known challenge in spatial datasets, the geographically weighted regression (GWR) approach (Fotheringham et al., 2002) was also exploited. GWR is a relatively recent modelling technique that overcomes issues related to spatial heterogeneity by allowing regression estimates to vary from location to location. In particular, the OLS model (eq. 1) can be converted to the GWR model (eq. 2) as follows:

$$
\begin{aligned}
& y=b_{0}+b_{1} x_{1}+\varepsilon \\
& y_{i}=b_{0}\left(u_{i}, v_{i}\right)+b_{1}\left(u_{i}, v_{i}\right) x_{1}+\varepsilon\left(u_{i}, v_{i}\right)
\end{aligned}
$$

where $y$ is the dependent variable, $x$ the independent variable, $b_{0}$ the intercept, $b_{1}$ the parameter estimate, $\varepsilon$ the model error, $i$ the location and $u, v$ the coordinates. In the present study, GWR modelling was performed by using adaptive bandwidth, determined by minimising $\mathrm{AIC}_{\mathrm{c}}$, and the bi-square kernel function. An optimal set of independent variables for the multiple GWR model was chosen as described by Gollini $e t$ al. (2015). An optimal bandwidth was re-calibrated each time in order to obtain a more refined model. The Monte Carlo randomisation tests with 999 permutations were used to test for significance of the spatial variability of GWR model parameter estimates. Mixed GWR modelling (Mei et al., 2004), which allows some predictors to be constant, was then applied if parameter estimates of an independent variable did not vary spatially according to the randomisation test.

In all multiple models, several interactions were assessed. In the event of a significant interaction, simple-slopes analysis was conducted and its results plotted. All models underwent the diagnostics of spatial autocorrelation of residuals by means of Moran's I test. Since multicollinearity was likely, its presence was checked by means of global and local variance inflation factors (VIFs); VIFs $<4$ were considered acceptable (Miles and Shevlin, 2001). All analyses were performed in the R environment (R Core Team, 2014).

\section{Results}

\section{Pharmacies in Liguria}

A total of 605 pharmacies were identified, corresponding to 0.38 pharmacies per 1000 inhabitants and 0.11 pharmacies per $\mathrm{km}^{2}$. At the provincial level, both indicators of density of pharmacies were unevenly distributed (Ph/Inhab: 0.36, 0.43, 0.37, 0.37 and $\mathrm{Ph} / \mathrm{km}^{2}:$ 0.07, 0.08, 0.18, 0.09 in Imperia, Savona, Genoa and La Spezia, respectively). At the municipal level, this gap was much wider ( $\mathrm{Ph} /$ inhab: 0-11.07/1000 inhabitants; $\mathrm{Ph} / \mathrm{km}^{2}: 0-0.90 / \mathrm{km}^{2}$ ) and highly positively skewed (a skewness coefficient of 5.58 and 2.52 for $\mathrm{Ph} / \mathrm{lnhab}$ and $\mathrm{Ph} / \mathrm{km}^{2}$, respectively). Mapping of the cube-root-transformed study outcomes is shown in Figure 1.

A total of 43/235 (18.3\%) municipalities did not have a pharmacy of their own; these were asymmetrically distributed among the four provinces: $7.2 \%(5 / 69), 9.4 \%(3 / 32), 14.9 \%(10 / 67)$ and $37.3 \%(25 / 67)$ in Savona, La Spezia, Genoa and Imperia, respectively. In these municipalities, the mean distance to the nearest pharmacy was 6.8 (SD 3.7)

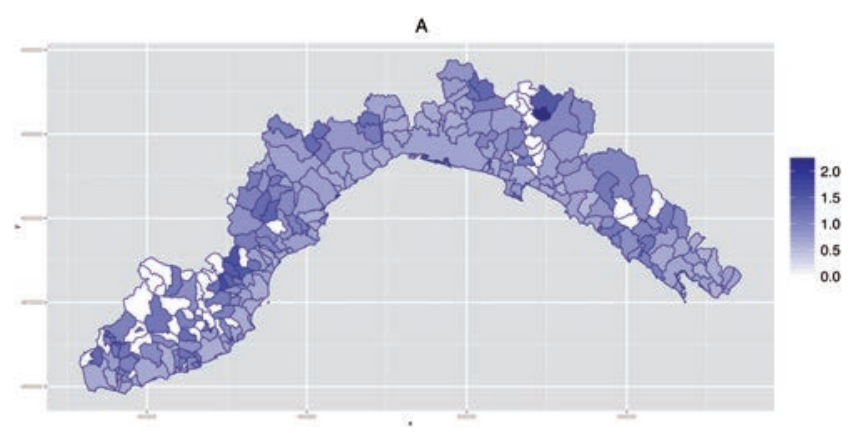

B

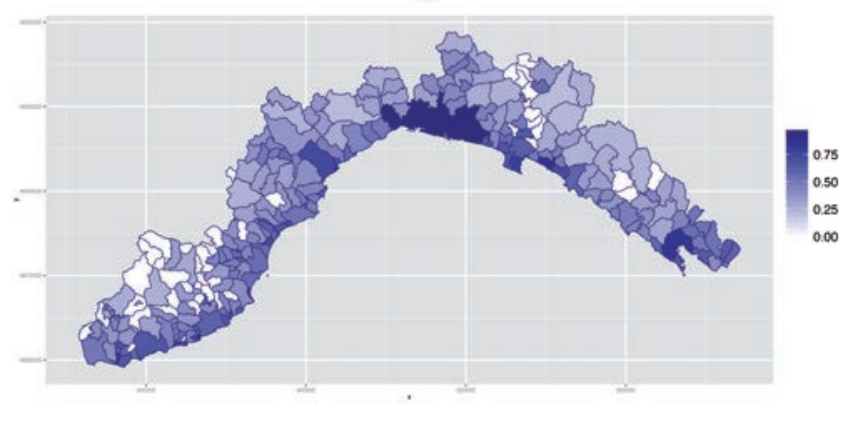

Figure 1. Distribution of community pharmacies per 1000 inhabitants (A) and $\mathrm{km}^{2}$ (B) in Ligurian municipalities. Data transformed by means of cube root transformation. 
$\mathrm{km}$, corresponding to 11.3 (SD 6.3) min of driving. All municipalities without a pharmacy belonged to totally/partially mountainous categories, while only $75.0 \%$ of municipalities with at least one pharmacy belonged to these categories (Fisher's exact test: $\mathrm{P}<0.001)$. A more detailed analysis revealed that the mean altitude [396.2 (SD 225.6) $\mathrm{m}$ ] of the municipalities with at least one pharmacy was significantly lower $(t=6.63, \mathrm{P}<0.001)$ than that [698.1 (SD 278.8) m] of municipalities without a pharmacy, and the effect size was large $[d=1.12(95 \%$ CI: 0.77-1.47)].

\section{Spatial autocorrelation analysis}

The global spatial autocorrelation analysis of the density of pharmacies revealed a modest but highly significant $(\mathrm{P}=0.001)$ clustered pattern: Moran's I of $\mathrm{Ph} / \mathrm{Inh}$ ab and $\mathrm{Ph} / \mathrm{km}^{2}$ were 0.082 and 0.295 , respectively. The local spatial autocorrelation analysis of $\mathrm{Ph} / \mathrm{Inhab}$ (Figure 2A) identified 27 municipalities with a significant clustered pattern $(\mathrm{N}=7$ hot spots and $\mathrm{N}=20$ cold spots), while 14 were significant outliers ( $\mathrm{N}=8$ hot-cold and $\mathrm{N}=6$ cold-hot). Both clusters and outliers were situated in the mountainous hinterland. The hot spots were located in the Province of Savona, while the cold spots were concentrated in the Provinces of Imperia and Genoa. The local spatial autocorrelation analysis of $\mathrm{Ph} / \mathrm{km}^{2}$ (Figure 2B) showed evident coast-hinterland and urban-rural patterns: 21 of 24 significant hot spots were coastal municipalities, including all four provincial capitals, while all significant $(\mathrm{N}=32)$ cold spots were municipalities located in the hinterland. Only five significant outliers ( $\mathrm{N}=2$ hot-cold and $\mathrm{N}=3$ cold-hot) were identified.

\section{Predicting the density of pharmacies: global models}

Table 1 reports simple OLS models for establishing relationships between the density of pharmacies and the independent variables of interest. A significantly negative association emerged between $\mathrm{Ph} / \mathrm{inh}$ ab on the one hand and both the mean altitude and the proportion of elderly residents on the other, while a higher municipal income determined a higher $\mathrm{Ph} / \mathrm{inh}$ ab. However, these models explained only a small $(<3 \%)$ amount of variance. All but one ( $\%$ of immigrants) of the simple OLS models for predicting $\mathrm{Ph} / \mathrm{km}^{2}$ proved highly significant
$(\mathrm{P}<0.001)$ : the association with population, coastal location, proportion of $<5$ year olds and income was positive, while it was negative with respect to mean altitude, rural status and percentage of elderly residents. Residuals of all univariate OLS models were significantly $(\mathrm{P}<0.01)$ spatially auto-correlated. Notably, the independent variable of mean altitude explained the highest proportion of variance in predicting both the indicators of density of pharmacies (Table 1).

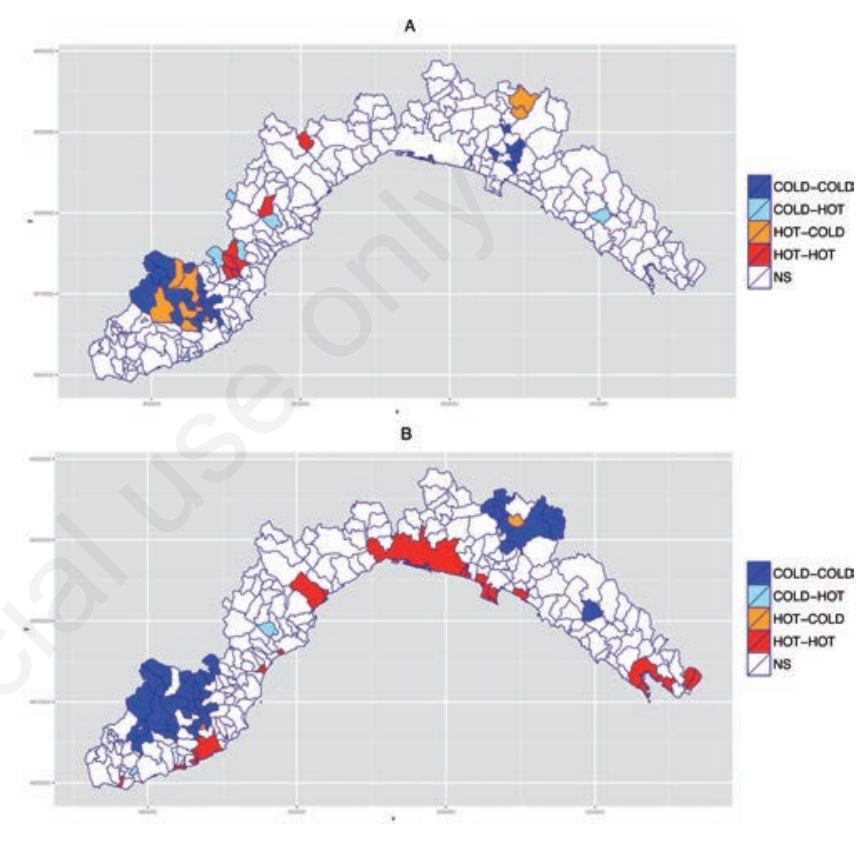

Figure 2. Local spatial autocorrelation analysis of community pharmacies per 1000 inhabitants $(A)$ and $\mathrm{km}^{2}(B)$ in Ligurian municipalities. Data transformed by means of cube root transformation.

Table 1. Unadjusted ordinary least-squares models to predict the density of community pharmacies.

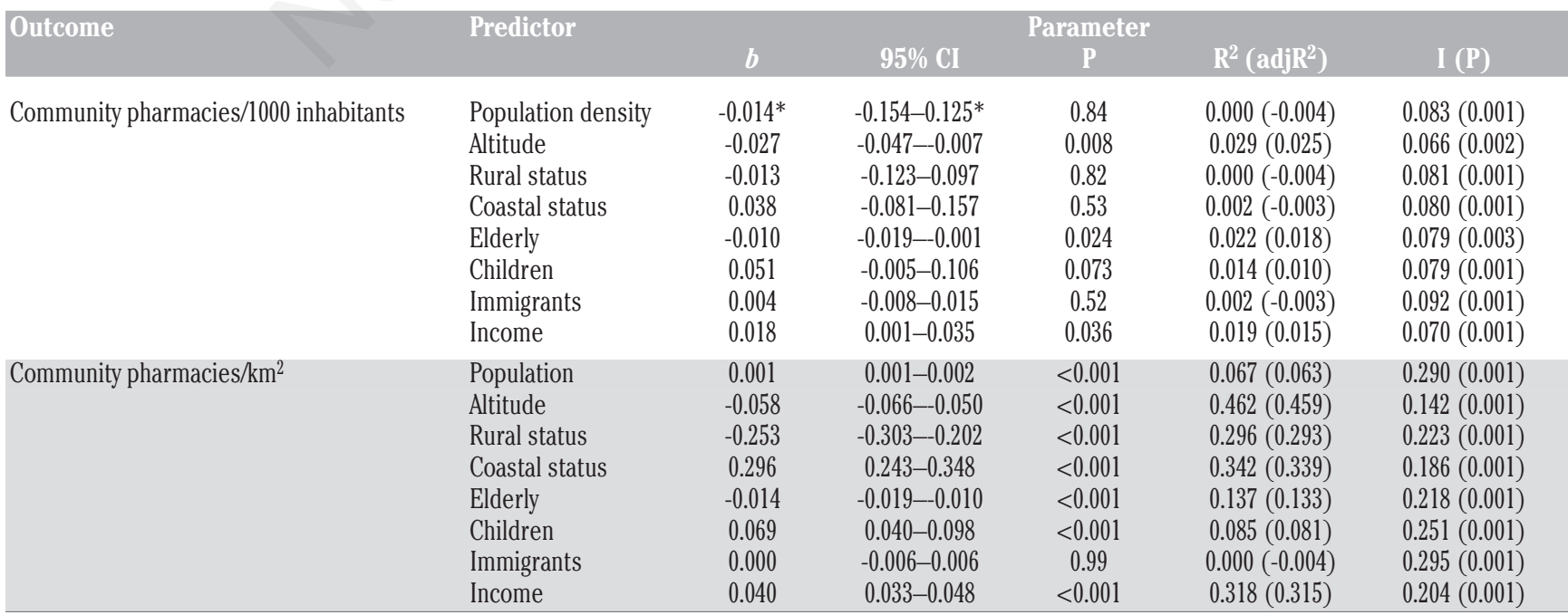

CI, confidence interval. *Coefficients multiplied by 1000 . 
The best-fitting multiple OLS model for predicting $\mathrm{Ph} /$ inhab in Liguria incorporated the independent variables of mean altitude and income level and their interaction. As shown in Table 2, higher income was associated with higher $\mathrm{Ph} / \mathrm{inhab}$, while mean altitude was no longer statistically significant $(\mathrm{P}=0.93)$. The altitude-by-income interaction term was also highly $(\mathrm{P}<0.001)$ positively significant, indicating that the impact of income level on $\mathrm{Ph} / \mathrm{inh}$ ab depended on municipal altitude. The model explained approximately $8 \%$ of variance (Table 2 ). Residuals of the model were still significantly $(\mathrm{P}=0.024)$ spatially autocorrelated ( $I$ value of 0.042 ). No signs of multicollinearity were detected (VIFs of 1.71, 1.87 and 1.53 for mean altitude, municipal income and interaction term, respectively). As shown by the simple-slopes analysis (Figure 3), the association between $\mathrm{Ph} /$ inhab and income was significantly $(\mathrm{P}<0.001)$ positive $(b=0.073)$ among municipalities located at high ( $+1 \mathrm{SD}$ above the mean) altitudes, while no association $(\mathrm{P}=0.37)$ was observed among lower-lying ( -1 SD below the mean) municipalities. The selected multiple OLS model with the outcome of $\mathrm{Ph} / \mathrm{km}^{2}$ contained more predictors and explained approximately $60 \%$ of the variance. Model coefficients were significantly positive for population, coastal location and income, while they were significantly negative for mean altitude and proportion of the elderly (Table 3 ). Although the altitude-by-income interaction was not significant, the analysis of simple slopes demonstrated that the relationship between $\mathrm{Ph} / \mathrm{km}^{2}$ and income level was significantly $(\mathrm{P}=0.014)$ positive $(b=0.019)$ among municipal- ities located at high altitudes, while it was not significant $(\mathrm{P}=0.089)$ among those situated at lower altitudes (Figure 4). Model diagnostics revealed no substantial multicollinearity (VIFs in a range of 1.06-2.81), although spatial autocorrelation was present $(I=0.097, \mathrm{P}=0.001)$.

\section{Predicting the density of pharmacies: mixed geographically weighted regression}

The best-fitting GWR model for predicting Ph/inhab contained the independent variables of mean altitude, proportion of the elderly and immigrants and income level. The model explained $24.8 \%$ of the variance, significantly outperforming the multiple OLS model $\left(\triangle \mathrm{adj} R^{2}: 0.08\right.$ $\triangle$ AICc: -7.22). The introduction of interaction terms worsened model fit. Residuals of the GWR model were spatially independent $(I=-0.0002$, $\mathrm{P}=0.41$ ) and no concerns regarding multicollinearity were detected (maximum local VIFs of 2.69, 1.74, 1.28 and 1.79 for mean altitude, proportion of the elderly and immigrants and income level, respectively). The Monte Carlo simulation showed a significant variability of local estimates for intercept $(\mathrm{P}=0.048)$, mean altitude $(\mathrm{P}=0.037)$ and percentage of immigrants $(\mathrm{P}=0.046)$, while it did not for the proportion of elderly residents $(\mathrm{P}=0.16)$ and income level $(\mathrm{P}=0.54)$. The last two predictors were therefore inserted as global terms in a mixed GWR model (Table 4), which determined a slight improvement ( $\triangle$ AICc: -1.1$)$. As shown by the choropleth maps in Figure $5 \mathrm{~A}$, the association between $\mathrm{Ph} / \mathrm{inhab}$ and

Table 2. Multiple ordinary least-squares regression model to predict the number of community pharmacies per 1000 inhabitants.

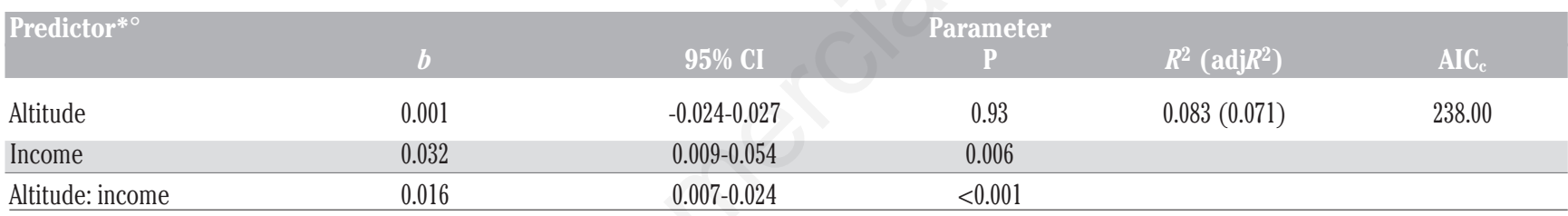

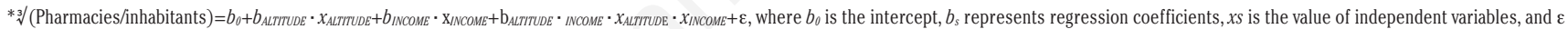
is the random error; ${ }^{\circ}$ independent variables are mean-centred.

Table 3. Multiple ordinary least-squares regression model to predict the number of community pharmacies per $\mathbf{k m}^{2}$.

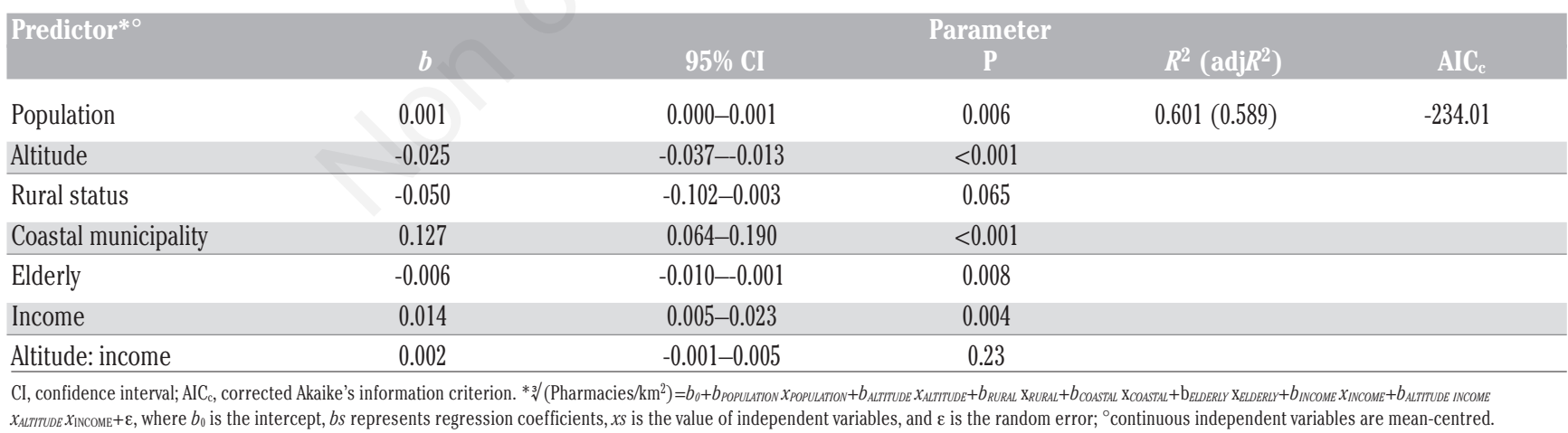

Table 4. Final mixed geographically weighted model to predict the number of community pharmacies per 1000 inhabitants.

\begin{tabular}{llccc} 
& Predictor* & & \multicolumn{2}{c}{ Parameter } \\
Global & Elderly & $b$, estimate & $b$, median (IQR) & - \\
& Income & -0.006 & - & - \\
Local & Altitude & 0.018 & $0.026(-0.053-0.033)$ & $-0.062-0.074$ \\
& Immigrants & - & $0.019(0.004-0.034)$ & $-0.008-0.042$ \\
\hline
\end{tabular}

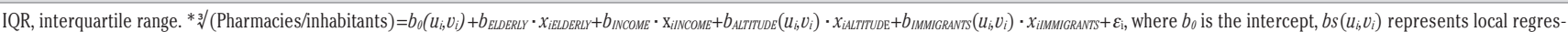
sion coefficients in municipality i with coordinates $\left(u_{i}, v_{i}\right), b s$ represents global regression coefficients, $x_{i}$ is the value of independent variables in municipality $i$, and $\varepsilon$ is the random error. 
mean altitude displayed a high level of spatial variability, the regression coefficients being mostly positive in the eastern part of the region (especially on the border between Genoa and Savona) and highly negative in the westernmost part, roughly corresponding to Imperia Province (especially in the inland Arroscia Valley). By contrast, the association between the relative numbers of foreign-born people and $\mathrm{Ph} /$ inhab was positive across almost the whole region and the estimates were relatively high in the eastern part of the Genoa (Figure 5B).

$\mathrm{Ph} / \mathrm{km}^{2}$ was best predicted by the explanatory variables of population, mean altitude, rural status and income level, and the model showed a significant improvement over the multiple OLS model $\left(\Delta \operatorname{adj} R^{2}: 0.06\right.$ $\triangle$ AICc: -4.72). There were no problems with regard to model diagnostics $(I=-0.023, \mathrm{P}=0.80$; maximum local VIFs in the range of 2.51-3.10).

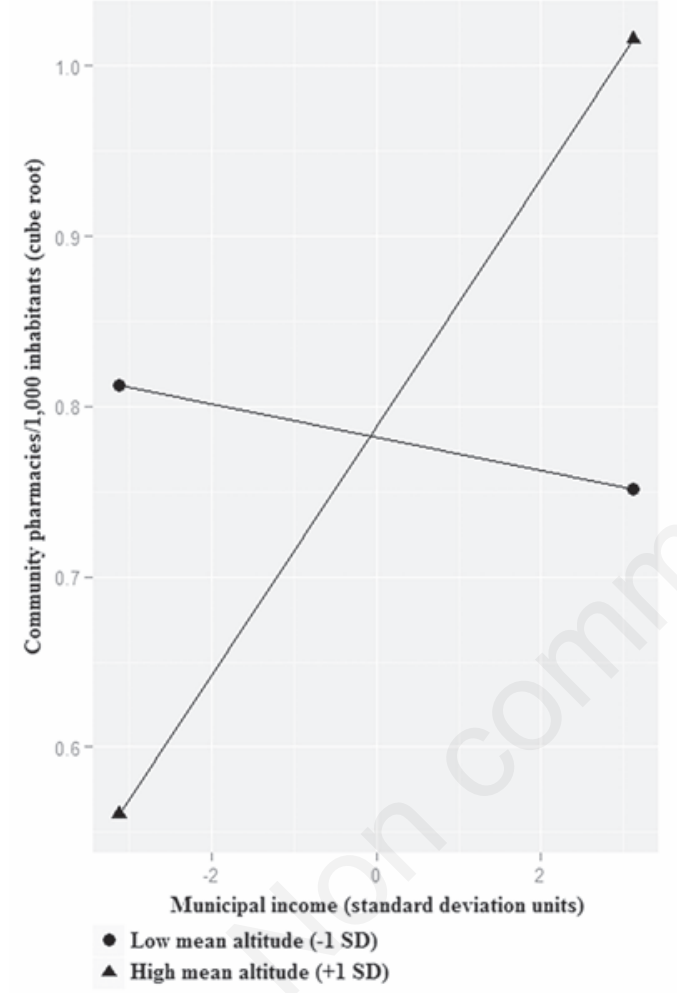

Figure 3. Simple slopes of municipal income predicting the number of community pharmacies per 1000 inhabitants at different levels of municipal altitude.
The randomisation test showed a significantly high variation in the local coefficients for population $(\mathrm{P}<0.001)$, altitude $(\mathrm{P}<0.001)$ and rural status $(\mathrm{P}=0.006)$; by contrast, estimates of the model intercept and the predictor income level varied little $(\mathrm{P}=0.27$ and $\mathrm{P}=0.51$, respectively). The final mixed GWR model is shown in Table 5 ; in comparison with the GWR model containing all local variables, the mixed model showed a significant improvement $(\triangle \mathrm{AIC}$ : -5.5$)$. The relationship between $\mathrm{Ph} / \mathrm{km}^{2}$ and population was highly positive (local $b$ s of 0.10 0.20 ) only in a few municipalities of the Arroscia valley, while these regression coefficients tended to zero in the overwhelming majority of the Liguria municipalities (Figure 6A). Conversely, municipal altitude was consistently negatively associated with $\mathrm{Ph} / \mathrm{km}^{2}$ across the whole study area, with about an 11-fold variation in parameter estimates, the

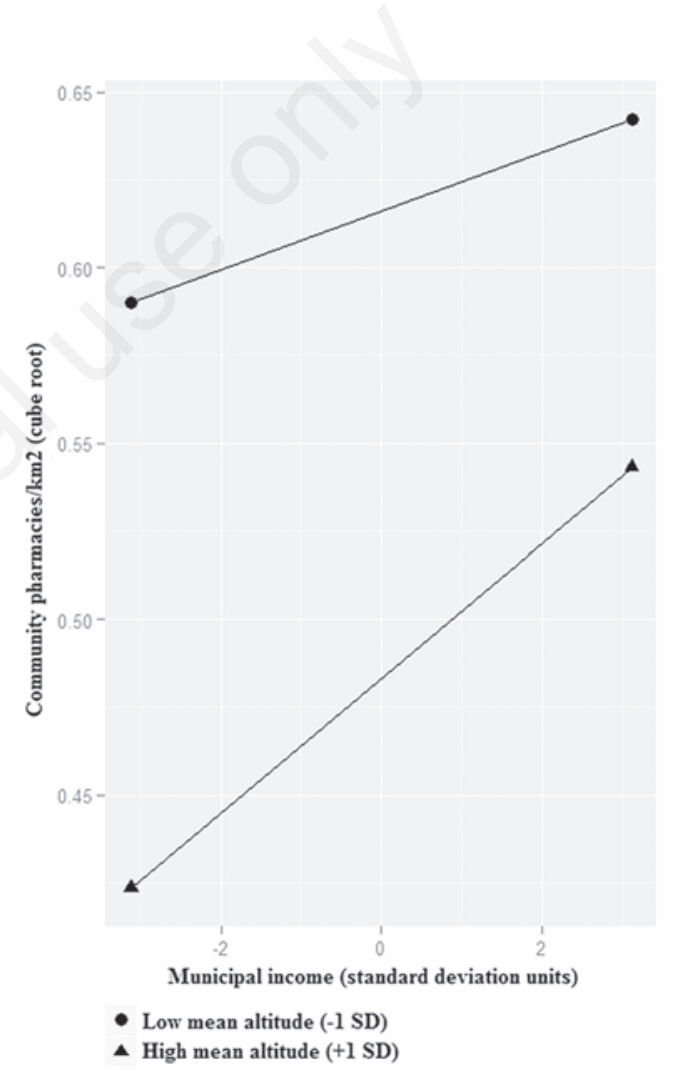

Figure 4. Simple slopes of municipal income predicting the number of community pharmacies per $\mathrm{km}^{2}$ at different levels of municipal altitude.

Table 5. Final mixed geographically weighted model to predict the number of community pharmacies per $\mathrm{km}^{2}$.

\begin{tabular}{|c|c|c|c|c|}
\hline & Predictor* & $b$, estimate & $\begin{array}{c}\text { Parameter } \\
b, \text { median (IQR) }\end{array}$ & $b, \min -\max$ \\
\hline Global & Income & 0.011 & - & - \\
\hline Local & $\begin{array}{l}\text { Population } \\
\text { Altitude } \\
\text { Rural status }\end{array}$ & $\begin{array}{l}- \\
- \\
-\end{array}$ & $\begin{array}{c}0.003(0.002-0.004) \\
-0.004(-0.052--0.030) \\
-0.077(-0.135--0.037)\end{array}$ & $\begin{array}{c}0.001-0.204 \\
-0.080-0.007 \\
-0.386-0.116\end{array}$ \\
\hline
\end{tabular}

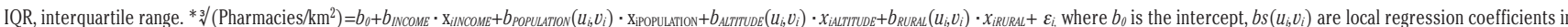
municipality i with coordinates $\left(u_{i} v_{i}\right)$, bs represents global regression coefficients, xis is the value of independent variables in municipality $i$, and $\varepsilon$ is the random error. 
highest being in Imperia (Figure 6B). The status of rural municipality exerted a negative effect on $\mathrm{Ph} / \mathrm{km}^{2}$ in some municipalities in Arroscia Valley and the eastern part of Genoa (Figure 6C).

\section{Discussion}

\section{Key findings and comparison with previous research}

We show here that the distribution of pharmacies (both $\mathrm{Ph} / \mathrm{inhab}$ and $\mathrm{Ph} / \mathrm{km}^{2}$ ) in Liguria follows a modest but significant clustered pattern, identifying possible under-supplied areas, generally corresponding to less affluent, small mountainous municipalities. It is known that spatial disparities in accessibility to healthcare resources are almost unavoidable owing to constraints of various nature (Delamater et al., 2012), especially in areas with particular topographic features and scattered small mountain villages as typified by Liguria. However, assessing geographical accessibility undoubtedly helps to identify areas characterised by lower or higher access possibilities, which is an essential step towards mitigating such disparities (Apparicio et al., 2008). This documentation should be useful for decision-makers, healthcare planners and other stakeholders with respect to the consequences following opening, closing or relocating facilities including change of the spectrum of services offered (Delamater et al., 2012).

Our analysis shows that both socio-economic and landscape characteristics are associated with both indicators of the geographical accessibility to pharmacies. While urban-rural inequalities in pharmaceutical supply have been established in several studies carried out in different geographic settings (Lin, 2004; Norris et al., 2014; Todd et al., 2014), the present study highlights the fact that, in coastal and hilly-
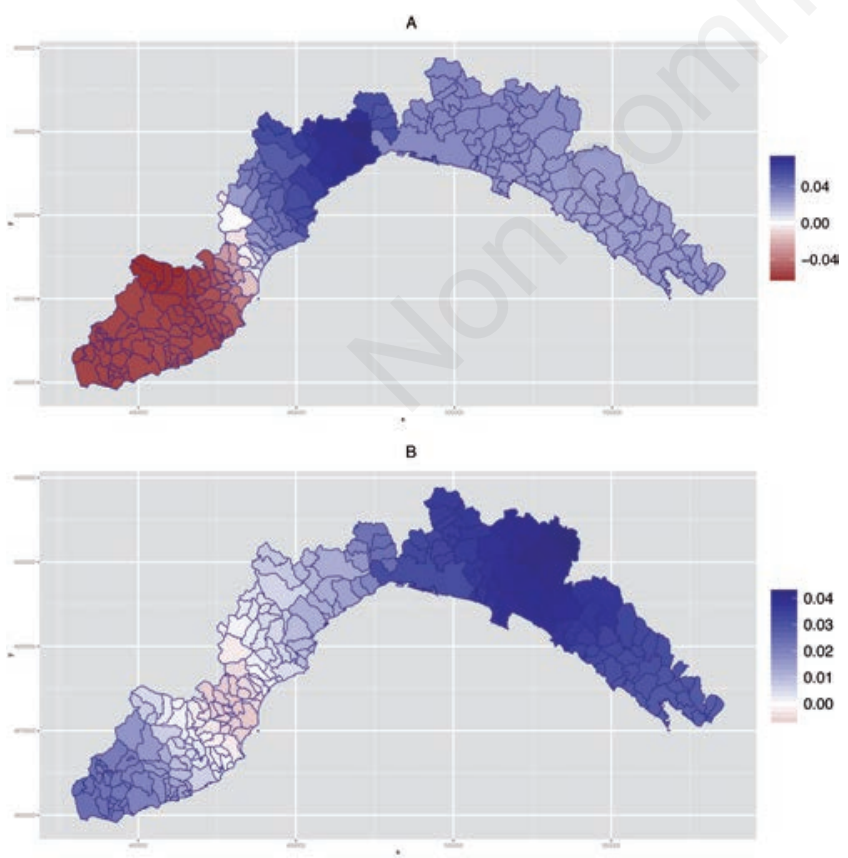

Figure 5. Local parameter estimates for the mean altitude (A) and proportion of immigrants (B) in the mixed geographically weighted model to predict the number of community pharmacies per 1000 inhabitants in Ligurian municipalities. mountainous regions such as Liguria, location (coastal/mountainous) may be an independent predictor of healthcare supply. Indeed, differences in accessibility were observed between plains and mountainous places, and between coastal and hinterland areas. This is in line with the results of local spatial autocorrelation analysis, since most coldspots were situated in inland municipalities, mostly in the region's highest mountain ranges: Marguareis Alps and Ligurian Apennines. Moreover, we found that the effects of economic status and altitude were not simply additive (especially in the model for predicting $\mathrm{Ph} /$ inhab): wealthier municipalities had a higher density of pharmacies, but this relationship depended on height, being significant only in locations at a relatively high altitude. These findings are also consistent with previous studies on healthcare services (Liu et al., 2011; Fang et al., 2014). Fang et al. (2014) have in fact established that economic determinants influence the utilisation of healthcare services to a greater extent in mountainous regions than in the plains. Analogously, Liu et al. (2011) have reported that maternal healthcare utilisation is closely related to both wealth and altitude. In our opinion, the difference in $\mathrm{Ph} / \mathrm{km}^{2}$, observed between coastal and interior municipalities, is probably linked to migration from inland to coastal areas (Gandolfo, 2005 ) and to the relatively scant and constantly declining agricultural

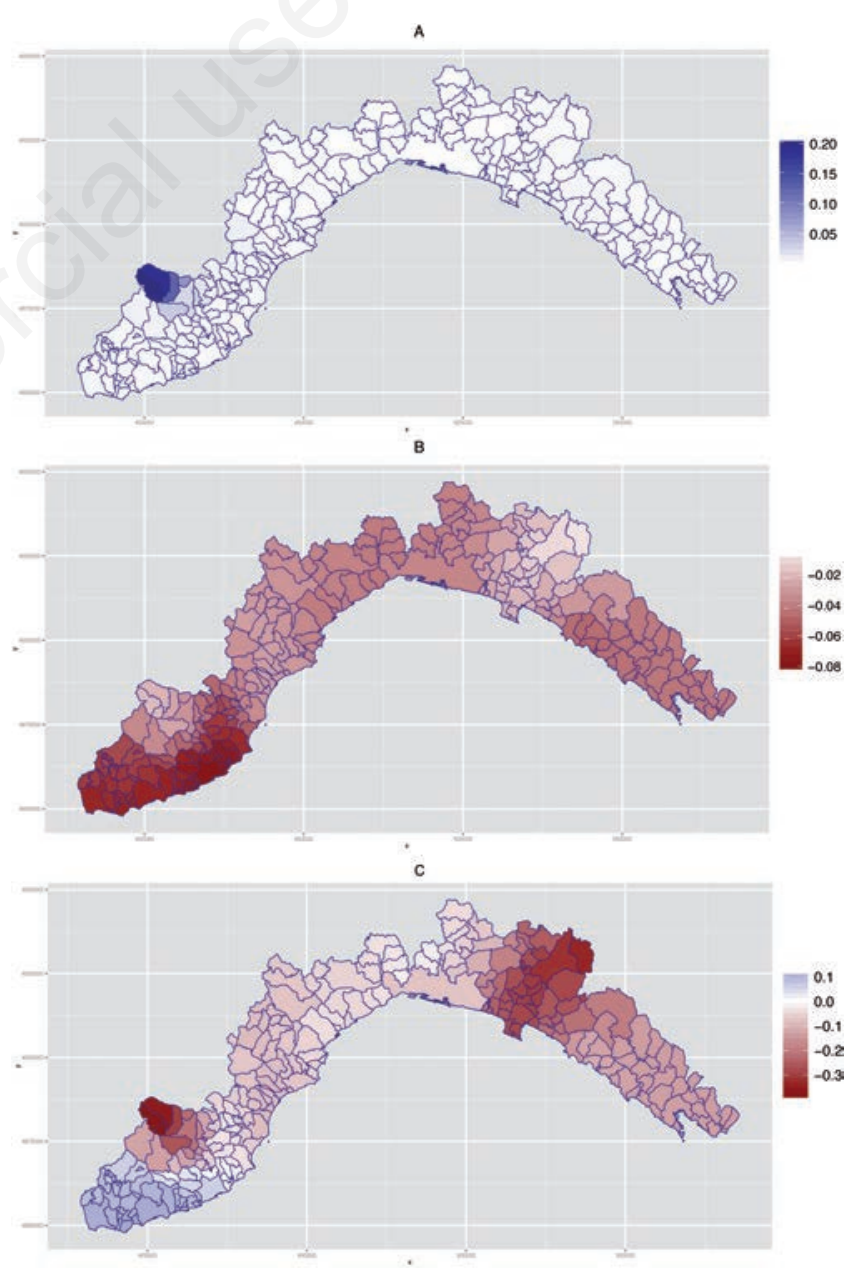

Figure 6. Local parameter estimates for population (A), mean altitude $(B)$ and status of rural municipality $(C)$ in the mixed geographically weighted model to predict the number of community pharmacies per $\mathrm{km}^{2}$ in Ligurian municipalities. 
activity in Liguria's mountainous areas (Liguria Ricerche, 2011). Another possible explanation may lie in the predominance of seaside tourism in Liguria (unlike mountain tourism in other Italian Alpine regions) and the consequent relative increase in population during the summer (Liguria Region, 2015). As a result, entrepreneurial activities may be more compromised in landlocked municipalities. Moreover, a study (Perez and Decoupigny, 2009) on access to healthcare in the southern part of the Alps (including the French Alpes-Maritime's and the Italian provinces Cuneo and Imperia), has demonstrated coast-hinterland disparities in access to pharmacies. With regard to the tertiary sector, a gap between the hinterland and the coast has also been described by some authors (Jordan, 2000; Andriotis, 2006).

Municipalities with a higher proportion of elderly residents displayed lower values of $\mathrm{Ph} / \mathrm{km}^{2}$, which potentially increases travelling time; it is thus not surprising that greater distance is associated with lower utilisation of healthcare facilities, including pharmacies as shown by Nemet and Bailey (2000) and Hiscock et al. (2008). Proximity to a pharmacy is of particular importance to the elderly; in one survey, Italian seniors living in both urban and rural areas ranked the availability of a pharmacy in $2^{\text {nd }}$ place (after food stores) (Marcellini et al., 2007). The elderly need pharmacies more than the general population (Lin, 2004); indeed, more than $90 \%$ of elderly people in Italy take at least one medicine on a long-term basis (Pilotto et al., 2006). The elderly are also less likely to utilise health services when they feel unwell (Fang et al., 2014). It may be argued that older adults in Italy have access to cars, either as drivers or as passengers (Mollenkopf $e t$ al., 2004; Marcellini et al., 2007). However, senior citizens often give up driving (Hakamies-Blomqvist and Wahlström, 1998) or at least reduce it (Raitanen et al., 2003) for several reasons including health-related ones, and their journeys become shorter and closer to home (Whelan et al., 2006). Moreover, mountain roads may be dangerous (Fu et al., 2011), especially in the winter. In addition, more than a quarter of the elderly in Italy live alone (National Observatory on Health Status in the Italian Regions, 2009), which reduces their transport options; even those living with their families may be reluctant to ask to be driven somewhere (Adler and Rottunda, 2006). The above-mentioned factors may contribute to under-utilisation of healthcare facilities and nonadherence to medical prescriptions. In this regard, the ability to drive and the distance to pharmacies have been found to be the only determinants of non-adherence to medication among patients with epilepsy (Welty et al., 2010).

Although most mountainous inland municipalities have a relatively low population density, this was not found to be associated with $\mathrm{Ph} /$ inhab confirming the report by Mangano (2010) that population density is not the main predictor, at least not in Italy, of pharmacy location. Indeed, the study by Mangano (2010), which was conducted in the Province of Catania, Sicily, has established that pharmacies are often opened independently from population density. Of note, Catania Province is also characterised by a substantial between-municipality difference in altitude.

\section{Usefulness of geographically weighted regression in modeling the density of pharmacies}

The usefulness of GWR in studying issues of spatial accessibility to primary healthcare has already been demonstrated (Bagheri et al., 2009). In our hands, the GWR approach outperformed the OLS models by being capable to completely reset the residual spatial autocorrelation frequent in spatial datasets. It allowed us to highlight the fact that relationships between the density of pharmacies and some predictors varied significantly across Liguria. We found that the relationship between municipal altitude and both indicators of the density of phar- macies was highly negative in several municipalities of the westernmost province of Imperia, many of which corresponded to the coldspots revealed in the local spatial autocorrelation analysis. Similarly, the rural status of a municipality was highly and negatively associated with $\mathrm{Ph} / \mathrm{km}^{2}$ in two distinct inland areas. Local coefficients for the percentage of immigrants showed somewhat opposite patterns, in that the eastern half of Liguria had much higher values that the western half. This could be explained by the uneven distribution of immigrants in Italy (Bratti and Conti, 2013). Indeed, foreign-born residents are less numerous in eastern provinces (Genoa and La Spezia) than in the western ones (Savona and Imperia). Interestingly, in the GWR model predicting $\mathrm{Ph} / \mathrm{inh}$ ab, both spatially varying explanatory variables also cut the region into halves along the longitude. It should be noted that the Ligurian coast has historically been subdivided into a eastern part (Riviera di Levante) and a western one (Riviera di Ponente) parts, which have distinct geographical features. On the other hand, while the above-described predictors varied spatially, municipal income and the proportion of elderly residents were constant across the study area, thus supporting the application of the mixed GWR approach.

\section{Deregulation and spatial accessibility to community pharmacies}

The 2012 deregulatory reform explicitly stated that, to ensure greater accessibility to pharmaceutical services and an equal distribution of pharmacies in a municipality, the Local Health Unit and the Order of Pharmacists must first be consulted in order to identify areas for new pharmacies. It was also underlined that the location of new pharmacies should guarantee accessibility to pharmaceutical services by residents of remote areas and those with low population density (Italian Republic, 2012). According to our spatial analysis, it seems that the most under-served zone in Liguria is situated in inland Imperia. This finding is in line with the analysis carried out by Farma.For (2012), which states that, as a result of deregulation, a total of 75 new pharmacies would be opened in Liguria, and that most of these $(\mathrm{N}=33$ or 0.15 new pharmacies/1000 inhabitants) should be located in the Imperia Province. By contrast, these proportions are substantially lower in the other provinces $(0.06,0.02$ and 0.05 new pharmacies/1,000 inhabitants in Savona, Genoa and La Spezia, respectively).

The country large study by Vogler et al. (2014) reveals that in countries having adopted deregulation policies (in primis Norway and Sweden, but also England, The Netherlands and Ireland) the number of pharmacies increased. However, the newly opened pharmacies were mostly concentrated in urban areas, which already had a high number of pharmacies in the pre-reform period, while no indications of improved accessibility in rural areas were found. In the 2.5 years following the Italian reform, only 5 new pharmacies were licensed in Liguria. Three of these were opened in small mountainous municipalities that did not previously have their own pharmacy. Paradoxically, another new pharmacy was opened in the city of Genoa, which, according to the new criterion, had previously been deemed to have an excess of 32 pharmacies (Farma.For, 2012). This pattern is consistent with the results reported by Wagner et al. (2009), who found that the deregulation reform in England had only slightly redressed the geographic imbalance in the distribution of pharmacies. Garattini et al. (2012) conclude that the Italian deregulatory reform is unlikely to benefit consumers, and that opening new small pharmacies will further aggravate financial pressure on the National Health Service in terms of reimbursements of the costs of medicines. Moreover, according to these authors, under-supplied municipalities could be treated exceptionally, for example by allowing general practitioners to dispense pharmaceuticals in more remote areas (Garattini et al., 2012). An interesting 
opportunity to improve access to pharmaceutical services in isolated and mountainous municipalities, especially those without their own pharmacy, could be the experimental project Farma-click launched by the Italian Ministry of Health. This project consists of installing automatic drug dispensers equipped with a camera; once the patient has described his or her symptoms directly to a pharmacist and/or scanned the doctor's prescription, the pharmacist authorises the machine to dispense the medicines required (OECD, 2009).

It has been noted that opening a rural pharmacy in every small village that lacks its own might not be necessary, since these municipalities are usually close to one another and it would not be difficult to reach a pharmacy in the vicinity (Garattini et al., 2012). Since walking is the most common means of locomotion among the elderly (Mollenkopf et al., 2004), it is obviously advantageous if the nearest pharmacy is situated within walking distance. Our analysis reveals, however, that considering a walkable distance of either $800 \mathrm{~m}$ (Guerra et al., 2012) or $1600 \mathrm{~m}$ (Villanueva et al., 2013), only 3 centroids of 43 in Liguria municipalities had the closest pharmacy within these distances. Moreover, walkability may be further compromised by the location of all 43 municipalities in mountainous areas.

The interpretation of our results is subject to some limitations. First of all, the outcome variables used in the present study are proxies of potential accessibility and, as such, refer to hypothetical rather than documented accessibility, which measures the actual utilisation of healthcare services by residents of a given area. Potential accessibility may underestimate travelling distances in both urban and rural areas (Lin et al., 2005). Indeed, Lin et al. (2005) have estimated that the travelling distance calculated by means of revealed access is at least twice that calculated by means of potential access. This implies that many people do not access the closest pharmacy, perhaps owing to inconvenient opening hours, personal preferences or financial issues. Secondly, although it has been suggested that analysing potential accessibility to pharmacies at the municipal level and focusing on remote areas may be optimal (Moïse and Docteur, 2007), the minimum local level in Italy is, theoretically, the census tract. Indeed, dividing large municipalities with this in mind would provide useful, more detailed information. However, data at the submunicipality level are rarely utilised in Italy and thus unrecoverable (Testi et al., 2005). Thirdly, the relatively low percentage of explained variance, especially in the models predicting $\mathrm{Ph} / \mathrm{inh}$ ab, suggests that other explanatory variables, e.g., density of general practitioners (Mangano, 2010) may be important in predicting the density of pharmacies. Finally, as in all observational studies, no causality can be inferred.

\section{Conclusions}

The results of the study presented here show that, in order to mitigate spatial access inequalities in Liguria, new drug-dispensing points should be established in mountainous inland zones, particularly in those municipalities without their own pharmacy. Considering that licensing and subsequent opening of new pharmacies in remote and sparsely populated areas may be economically disadvantageous (Garattini et al., 2012), and that such areas have relatively old populations and low rates of entrepreneurship, the implementation of alternative dispensing strategies look attractive. The density of pharmacies at the municipal level is associated with several socio-economic and landscape factors, some of which vary spatially, while others do not. In such situations, application of the mixed GWR technique is a valuable solution, and mapping its results may facilitate the work of policy-makers and healthcare planners.

\section{References}

Abolhallaje M, Mousavi SM, Anjomshoa M, Beigi Nasiri A, Seyedin H, Sadeghifar J, Aryankhesal A, Rajabi Vasokolaei G, Beigi Nasiri M, 2014. Assessing health inequalities in Iran: a focus on the distribution of health care facilities. Glob J Health Sci 6:285-91.

Adler G, Rottunda S, 2006. Older adults' perspectives on driving cessation. J Aging Stud 20:227-35.

Amstislavski P, Matthews A, Sheffield S, Maroko AR, Weedon J, 2012. Medication deserts: survey of neighborhood disparities in availability of prescription medications. Int J Health Geogr 11:48.

Andriotis K, 2006. Researching the development gap between the hinterland and the coast: evidence from the island of Crete. Tourism Manage 27:629-39.

Anselin L, 1995. Local indicators of spatial association. Geogr Anal 27:93-115.

Antitrust Authority, 1998. Regulation of pharmacies (advisory opinion). Available from: http://www.agcm.it/en/newsroom/pressreleases/1061-regulation-of-pharmacies-advisory-opinion.html

Apparicio P, Abdelmajid M, Riva M, Shearmur R, 2008. Comparing alternative approaches to measuring the geographical accessibility of urban health services: distance types and aggregation-error issues. Int $\mathrm{J}$ Health Geogr 7:7.

Bagheri N, Holt A, Benwell GL, 2009. Using geographically weighted regression to validate approaches for modelling accessibility to primary health care. Appl Spat Anal Policy 2:177-94.

Benrimoj SI, Frommer MS, 2004. Community pharmacy in Australia. Aust Health Rev 28:238-46.

Bratti M, Conti C, 2013. Immigration, population diversity and innovation of Italian regions. University of Milan, Milan, Italy.

Casey MM, Klingner J, Moscovice I, 2002. Pharmacy services in rural areas: is the problem geographic access or financial access? J Rural Health 18:467-77.

Delamater PL, Messina JP, Shortridge AM, Grady SC, 2012. Measuring geographic access to health care: raster and network-based methods. Int J Health Geogr 11:15.

Eurostat, 2015. Population statistics. Available from: http://ec.europa.eu/eurostat/web/population-demography-migration-projections/population-data/main-tables

Fang P, Han S, Zhao L, Fang Z, Zhang Y, Zou X, 2014. What limits the utilization of health services among the rural population in the Dabie Mountains - evidence from Hubei province, China? BMC Health Serv Res 14:379.

Farma.For, 2012. [Ecco quante farmacie apriranno per provincia/comune con il Quorum a 3300]. [Webpage in Italian]. Available from: http://quellichelafarmacia.com/3515/dati-ecco-quante-farmacieapriranno-per-provincia-comune-con-il-quorum-a-3300-link-per-ildownload/

Fotheringham S, Brunsdon C, Charlton M, 2002. Geographically weighted regression: the analysis of spatially varying relationships. Wiley, Hoboken, NJ, USA.

Fu R, Guo Y, Yuan W, Feng H, Ma Y, 2011. The correlation between gradients of descending roads and accident rates. Safety Sci 49:41623.

Gandolfo A, 2005. [La provincia di Imperia: storia, arti, tradizioni]. [Book in Italian]. BLU ed., Turin, Italy.

Garattini L, van de Vooren K, Curto A, 2012. Will the reform of community pharmacies in Italy be of benefit to patients or the Italian National Health Service? Drugs Ther Perspect 28:23-6.

Gollini I, Lu B, Charlton M, Brunsdon C, Harris P. GWmodel, 2015. An R 
package for exploring spatial heterogeneity using geographically weighted models. J Stat Softw 63:1-50.

Guerra E, Cervero R, Tischler D, 2012. The half-mile circle: does it best represent transit station catchments? Available from: http://escholarship.org/uc/item/68r764df

Hakamies-Blomqvist L, Wahlström B, 1998. Why do older drivers give up driving? Accid Anal Prev 30:305-12.

Hassanat AB, Abbadi MA, Altarawneh GA, Alhasanat AA, 2014. Solving the problem of the $\mathrm{k}$ parameter in the KNN classifier using an ensemble learning approach. Int J Comput Inf Sci 12:33-9.

Hiscock R, Pearce J, Blakely T, Witten K, 2008. Is neighborhood access to health care provision associated with individual-level utilization and satisfaction? Health Serv Res 43:2183-200.

Houghton F, 2005. Hiding the evidence: the State and spatial inequalities in health in Ireland. Irish Geogr 38:96-106.

Istat, 2014. [Atlante statistico dei comuni]. [Webpage in Italian]. Available from: http://www.istat.it/it/archivio/113712

Istat, 2015a. Demography in figures. Available from: http://demo.istat.it/index_e.html

Istat, 2015b. [Informazioni territoriali e cartografiche]. [Webpage in Italian]. Available from: http://www.istat.it/it/strumenti/territorioe-cartografia

Italian Republic, 2012. [Conversione in legge, con modificazioni, del decreto-legge 24 gennaio 2012, n. 1, recante disposizioni urgenti per la concorrenza, lo sviluppo delle infrastrutture e la competitività]. [Regulation in Italian]. In: Official Journal, L 19, 24/01/2012.

Jordan P, 2000. Restructuring Croatia's coastal resorts: change, sustainable development and the incorporation of rural hinterlands. J Sustain Tour 8:525-39.

Kumar N, 2004. Changing geographic access to and locational efficiency of health services in two Indian districts between 1981 and 1996. Soc Sci Med 58:2045-67.

Lemke D, Mattauch V, Heidinger 0, Hense HW, 2015. Who hits the mark? A comparative study of the free geocoding services of Google and 0penStreetMap. Gesundheitswesen 77:e160-5.

Liguria Region, 2015. Osservatorio turistico regionale. Available from: http://www.regione.liguria.it/argomenti/conoscere-e-vivere-il-territorio/turismo-e-cultura/osservatorio-turistico-regionale.html

Liguria Ricerche, 2011. [Agricoltura in Liguria. Rapporto sui dati provvisori del $6^{\circ}$ Censimento generale dell'agricoltura in Liguria]. [Document in Italian]. Available from: http://censimentoagricoltura.istat.it/fileadmin/template/main/res/Rapporto_sui_dati_pr ovvisori_.pdf

Lin SJ, 2004. Access to community pharmacies by the elderly in Illinois: a geographic information systems analysis. J Med Syst 28:301-9.

Lin SJ, Crawford SY, Warren Salmon J, 2005. Potential access and revealed access to pain management medications. Soc Sci Med 60:1881-91.

Liu X, Zhou X, Yan H, Wang D, 2011. Use of maternal healthcare services in 10 provinces of rural western China. Int J Gynaecol Obstet 114:260-4

Mangano A, 2010. Community pharmacies in the city area: evidence from an Italian province. Eur Plan Stud 18:485-96.

Marcellini F, Giuli C, Gagliardi C, Papa R, 2007. Aging in Italy: urbanrural differences. Arch Gerontol Geriat 44:243-60.

Mei CL, He SY, Fang KT, 2004. A note on the mixed geographically weighted regression model. J Regional Sci 44:143-57.

Miles J, Shevlin M, 2001. Applying regression \& correlation: a guide for students and researchers. SAGE Publ., Newcastle upon Tyne, UK.

Ministry of Economy and Finance, 2012. Available from: http://wwwl.finanze.gov.it/finanze2/pagina_dichiarazioni/dichiara zioni.php

Ministry of Health, 2015. Community pharmacies. Available from: $\mathrm{http} / / / w w w . d a t i . s a l u t e . g o v . i t / d a t i / d e t t a g l i o D a t a s e t . j s p ? m e n u=d a t i \&$ idPag $=5$

Moïse P, Docteur E, 2007. Pharmaceutical pricing and reimbursement in Mexico. OECD, Paris, France.

Mollenkopf H, Marcellini F, Ruoppila I, Széman Z, Tacken M, Wahl HW, 2004. Social and behavioural science perspectives on out-of-home mobility in later life: findings from the European project MOBILATE. Eur J Ageing 1:45-53.

Moran PAP, 1950. Notes on continuous stochastic phenomena. Biometrika 37:17-23.

National Observatory on Health Status in the Italian Regions, 2009. [Rapporto osserva salute 2009]. [Document in Italian]. Available from: http://www.cattolicanews.it/Rapporto_0sservasalute 2009_Salute_e_assistenza_anziani.pdf

Nemet GF, Bailey AJ, 2000. Distance and health care utilization among the rural elderly. Soc Sci Med 50:1197-208.

Norris P, Horsburgh S, Sides G, Ram S, Fraser J, 2014. Geographical access to community pharmacies in New Zealand. Health Place 29:140-5.

Odoi A, Busingye D, 2014. Neighborhood geographic disparities in heart attack and stroke mortality: comparison of global and local modeling approaches. Spat Spatiotemporal Epidemiol 11:109-23.

OECD, 2009. OECD rural policy reviews: Italy. OECD, Paris, France.

Perez S, Decoupigny F, 2009. A new analysis of access to healthcare reveals disparities in a cross-border population of the Southern European Alps. Available from: https:/hal.archives-ouvertes.fr/hal00449575/document

Pilotto A, Franceschi M, Vitale D, Zaninelli A, Masotti G, Rengo F, F.I.R.I., SOFIA Project Investigators, 2006. Drug use by the elderly in general practice: effects on upper gastrointestinal symptoms. Eur J Clin Pharmacol 62:65-73.

Qato DM, Daviglus ML, Wilder J, Lee T, Qato D, Lambert B, 2014. 'Pharmacy deserts' are prevalent in Chicago's predominantly minority communities, raising medication access concerns. Health Aff (Millwood) 33:1958-65.

R Core Team, 2014. R: a language and environment for statistical computing. R Foundation for Statistical Computing, Vienna, Austria.

Raitanen T, Törmäkangas T, Mollenkopf H, Marcellini F, 2003. Why do older drivers reduce driving? Findings from three European countries. Transp Res Part F Traffic Psych Behav 6:81-95.

Rice N, Smith PC, 2001. Ethics and geographical equity in health care. J Med Ethics 27:256-61.

Schuler M, Stucki E, Roque 0, Perlik M, 2004. Mountain areas in Europe: analysis of mountain areas in EU member states, acceding and other European countries. Nordic Centre for Spatial Development, Stockholm, Sweden.

Stopka TJ, Geraghty EM, Azari R, Gold EB, Deriemer K, 2013. Factors associated with presence of pharmacies and pharmacies that sell syringes over-the-counter in Los Angeles County. J Urban Health 90:1079-90.

Todd A, Copeland A, Husband A, Kasim A, Bambra C, 2014. The positive pharmacy care law: an area-level analysis of the relationship between community pharmacy distribution, urbanity and social deprivation in England. BMJ Open 4:e005764.

Testi A, Ivaldi E, Busi A, 2005. [Caratteristiche e potenzialità informative degli indici di deprivazione]. [Article in Italian]. Tendenze Nuove 2:111-24.

Villanueva K, Pereira G, Knuiman M, Bull F, Wood L, Christian H, Foster S, Boruff BJ, Beesley B, Hickey S, Joyce S, Nathan A, Saarloos D, 
Giles-Corti B, 2013. The impact of the built environment on health across the life course: design of a cross-sectional data linkage study. BMJ Open 3:e002482.

Vogler S, Habimana K, Arts D, 2014. Does deregulation in community pharmacy impact accessibility of medicines, quality of pharmacy services and costs? Evidence from nine European countries. Health Policy 117:311-27.

Wagner A, Hann M, Noyce P, Ashcroft D, 2009. Equity in the distribution of community pharmacies in England: impact of regulatory reform. J Health Serv Res Policy 14:243-8.

Ward K, Sanders D, Leng H, Pollock AM, 2014. Assessing equity in the geographical distribution of community pharmacies in South Africa in preparation for a national health insurance scheme. B World Health Organ 92:482-9.

Welty TE, Willis SL, Welty EA, 2010. Effect of limited transportation on medication adherence in patients with epilepsy. J Am Pharm Assoc 50:698-703.

Whelan M, Langford J, Oxley J, Koppel S, Charlton J, 2006. The elderly and mobility: a review of the literature. Accident Research Center, Monash University, Clayton, Australia.

WHO, 2001. How to develop and implement a national drug policy. WHO, Geneva, Switzerland.

Xu KT, Rojas-Fernandez CH, 2003. Ancillary community pharmacy services provided to older people in a largely rural and ethnically diverse region: a survey of consumers in West Texas. J Rural Health 19:79-86.

Yao N, Foltz SM, Odisho AY, Wheeler DC, 2015. Geographic analysis of urologist density and prostate cancer mortality in the United States. PLoS ONE 10:e131578. 